\title{
Low-temperature purification of the synthesis gas
}

\author{
Anatolii V. Korobeinikov ${ }^{1 *}$, and Sergey A. Shevyrev ${ }^{2}$ \\ ${ }^{1}$ Gorbachev Kuzbass State Technical University, 650000 Kemerovo, Russia \\ ${ }^{2}$ National Research Tomsk Polytechnic University, 30, Lenin Avenue, Tomsk, 634050, Russia
}

\begin{abstract}
In this paper, studies are made of the most economical method of low-temperature purification of synthesis gas, which is obtained during steam gasification of carbonizate. The analytical calculation is based on the cooling and phase transition of sulfur and carbon dioxide compounds and their separation. The paper presents the comparison of process energy costs depending on consumption characteristics and process parameters.
\end{abstract}

\section{Introduction}

Synthesis gas obtained in the process of steam oxygen-free gasification [1] is characterized by the content ( $\%$ by vol.) of the target $\mathrm{H}_{2}$ components equal to 62 , while $\mathrm{CO}$ - to 26 . In addition, it contains gases such as $\mathrm{CO}_{2}$ up to $12, \mathrm{H}_{2} \mathrm{~S}$ and $\mathrm{SO}_{\mathrm{x}}$ up to $1 \%$ by vol., which adversely affect the catalytic processes of obtaining various hydrocarbons. For the FischerTropsch process, most catalysts, including iron and cobalt, are extremely sensitive to "poisoning" with sulfur that is reflected in the shortening of their working life and deterioration of the process selectivity. As a result, it is impossible to reach the calculated technical and economic indicators and to ensure a low cost price of the products. In this connection, the most important is the purification of synthesis gas from sulfur compounds $\left(\mathrm{SO}_{\mathrm{x}}\right.$ and $\left.\mathrm{H}_{2} \mathrm{~S}\right)$ and $\mathrm{CO}_{2}$. Despite the relatively low concentration of sulfur compounds in the composition of synthesis gas (up to $1 \%$ by vol.) their content should be ensured up to 2 $\mathrm{mg} / \mathrm{m}^{3}[2]$.

\section{Statement of the problem}

The purpose of these studies is the energy analysis for the proposed method of purification of synthesis gas produced in the steam gasification carbonizate. It is proposed to purify the synthesis gas by selective desublimation/condensation of the components by discrete cooling. The implementation of such a method can compete with chemical methods of purification.

\footnotetext{
* Corresponding author: targenur@mail.ru
} 


\section{Process and schema description}

The gas is cooled to the phase transition temperature of its components at atmospheric pressure: $\mathrm{CO}_{2}$ - below $95 \mathrm{~K}, \mathrm{H}_{2} \mathrm{~S}$ - below $213 \mathrm{~K}$.

In order to investigate the physical methods of purification of synthesis gas, we used a principal scheme, shown in Fig. 1.

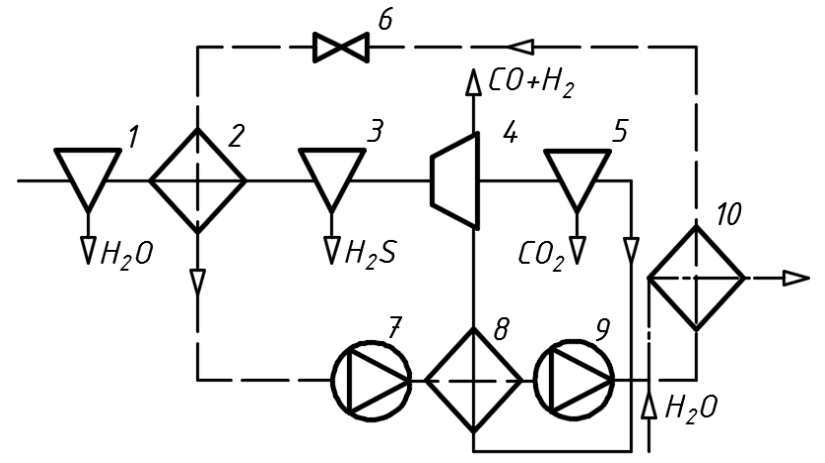

Fig. 1. The principal diagram of low-temperature purification of synthesis gas. The solid line is synthesis gas, the dashed line is the refrigerant cycle, the dash-dot line is water. $1,3,5$ - cyclone separators; 2, 8,10 - recuperative heat exchangers; 4 - turboexpander with a compressor on one shaft; 6 - a throttle washer; 7, 9-1 ${ }^{\text {st }}$ and $2^{\text {nd }}$ compression stages.

The calculation is carried out by the thermal balance method. Synthesis gas at the inlet to the unit is wet, the temperature is $323 \mathrm{~K}$, and the pressure is $101.3 \mathrm{kPa}$, without mechanical impurities. Dehumidification is carried out in the cyclone separator 1 . The gas is cooled to $203 \mathrm{~K}$ in the heat exchanger 2, i.e., $10 \mathrm{~K}$ below the condensation temperature of $\mathrm{H}_{2} \mathrm{~S}$ at atmospheric pressure. As a result, other sulfur compounds such as $\mathrm{SO}_{\mathrm{x}}$ are condensing in case of their availability [4]. To purify sulfur compounds in separator 3 , the gas must be cooled to $185 \mathrm{~K}$. At this temperature and atmospheric pressure, $\mathrm{CO} 2$ passes from the gas phase directly to the solid state, bypassing the liquid state, as a result of that the so-called "dry ice" is formed (Fig. 2).

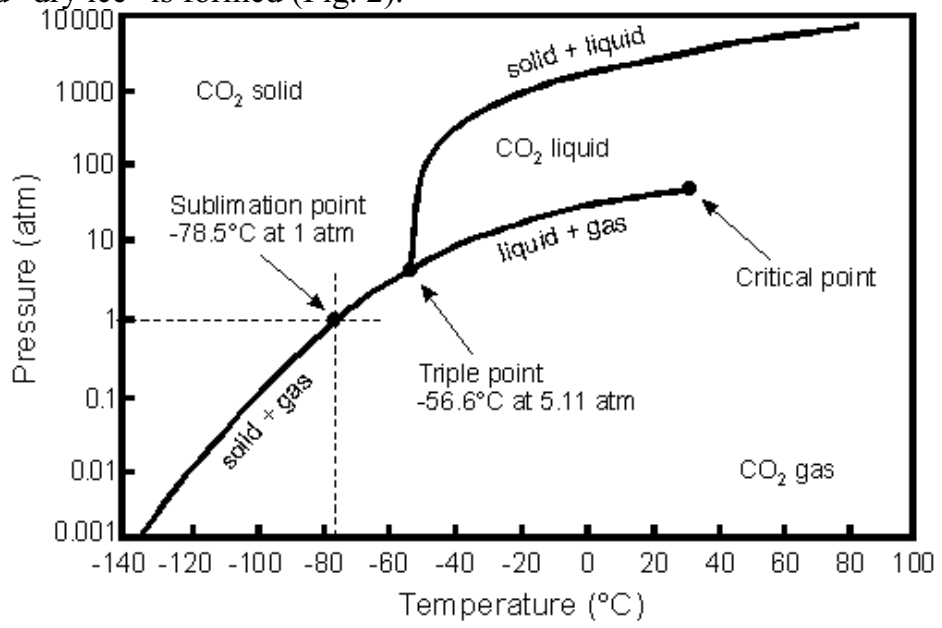

Fig. 2. Pressure-Temperature phase diagram for $\mathrm{CO}_{2}$. 
A turbo expander 4 must be used to achieve a temperature of $185 \mathrm{~K}$. The synthesis gas purified in a separator 5 is compressed in a compressor and sent to a Fischer-Tropsch reactor.

A refrigeration cycle is used for the heat removal in the heat exchanger 2. It includes two-stage compression 7 and 9 , an intercooler 8 , a condenser 10 and a throttle plate 6 . It is proposed to use R407a as a refrigerant.

\section{Results and discussion}

The synthesis gas flow rates are taken discretely equal to 5, 50, 500 and $5000 \mathrm{l} / \mathrm{min}$, at a pressure of $101.3 \mathrm{kPa}$. The heat calculation of the heat exchanger 2 and the calculation of the refrigeration cycle were made according to the scheme (Fig. 1), the corresponding results are summarized in Table. 1.

Table 1. Dependence of performance indicators on increase in the synthesis gas consumption.

\begin{tabular}{|c|c|c|c|}
\hline $\begin{array}{c}\text { The synthesis } \\
\text { gas flow rate, } \\
\mathbf{l} / \mathbf{m i n}\end{array}$ & $\begin{array}{c}\text { The amount of heat } \\
\text { removed from the synthesis } \\
\text { gas, } \mathbf{k W}\end{array}$ & $\begin{array}{c}\text { Heat which can be } \\
\text { utilized usefully, } \\
\mathbf{k W}\end{array}$ & $\begin{array}{c}\text { Power } \\
\text { consumption, } \mathbf{k W}\end{array}$ \\
\hline 5 & 0.0244 & 0.05063 & 0.0266 \\
\hline 50 & 0.2439 & 0.5063 & 0.266 \\
\hline 500 & 2.4391 & 5.063 & 2.66 \\
\hline 5000 & 24.3915 & 50.63 & 26.6 \\
\hline
\end{tabular}

It can be seen from the Table that $24.4 \mathrm{~kW}$ of heat should be removed for the separation of sulfur compounds from synthesis gas, at a flow rate of $5000 \mathrm{l} / \mathrm{min}$, with a cooling coefficient of 1.09. It is necessary to use lower temperatures to remove $\mathrm{CO}_{2}$ that can be achieved in a turbo-expander. In addition, the consumed power of the refrigerant compressors is $26.6 \mathrm{~kW}$, and it is necessary to raise the pressure of the synthesis gas feeding into the reactor to $2-3 \mathrm{MPa}$. It is proposed to carry out the purification process at an elevated pressure corresponding to the Fischer-Tropsch reaction process. The parameters of the gas purification process are presented in Table 2, while the schematic of the purification process is shown in Fig. 3.

Table 2. Phase transition temperatures depending on pressure.

\begin{tabular}{|c|c|c|}
\hline \multirow{2}{*}{$\begin{array}{c}\text { Pressure, } \\
\mathbf{M P a}\end{array}$} & \multicolumn{2}{|c|}{ Condensation temperature, $\mathbf{K}$} \\
\cline { 2 - 3 } & Carbon dioxide $-\mathbf{C O}_{\mathbf{2}}$ & Sulfur hydride $-\mathbf{H}_{\mathbf{2}} \mathbf{S}$ \\
\hline 0.1 & 195 (desublimation) & 212.7 \\
\hline 2 & 254 & 298 \\
\hline 3 & 268 & 315.3 \\
\hline
\end{tabular}

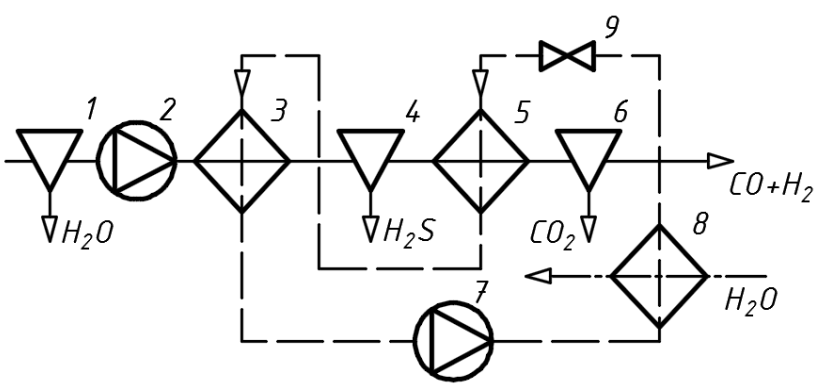

Fig. 3. The principal diagram of low-temperature purification of synthesis gas. The solid line is synthesis gas, the dashed line is the refrigerant cycle, the dash-dot line is water. $1,4,6$ - cyclone separators; 2, 7 - compressors; 3, 5, 8 - recuperative heat exchangers; 9 - throttle washer. 
There is no need to use a turboexpander, since the condensation temperature of $\mathrm{CO}_{2}$ is above $254 \mathrm{~K}$ that significantly reduces the capital costs of the installation. Calculations of the energy costs for the purification of synthesis gas against $\mathrm{CO}_{2}$ and $\mathrm{H}_{2} \mathrm{~S}$, depending on the gas flow rate at different pressures of the cooling process, are shown in Fig. 4, and at a flow rate of $5000 \mathrm{l} / \mathrm{min}$ in Table 3.

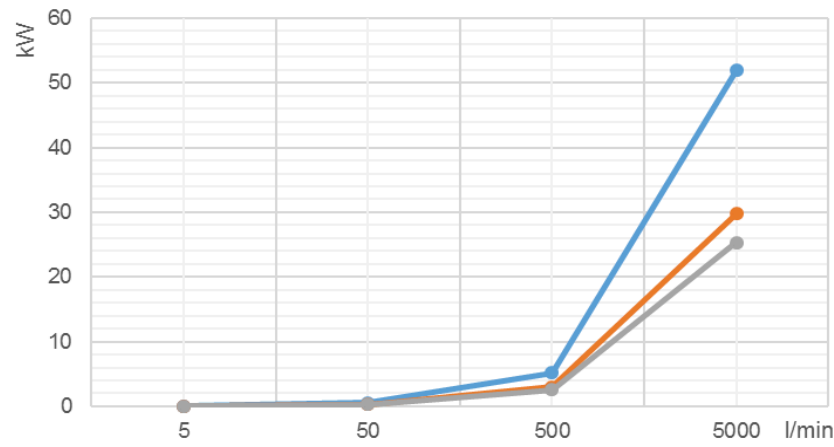

Fig. 4. Dependence of cooling capacity on consumption. Blue line (top) - cooling capacity at 0.1 $\mathrm{MPa}$, orange (in the middle) - at $2 \mathrm{MPa}$, gray (bottom) - at $3 \mathrm{MPa}$.

Table 3. Dependence of performance indicators on pressure increase at a consumption of synthesis gas equal to $5000 \mathrm{l} / \mathrm{min}$.

\begin{tabular}{|c|c|c|c|}
\hline $\begin{array}{c}\text { The synthesis } \\
\text { gas flow rate, } \\
\mathbf{l} / \mathbf{m i n}\end{array}$ & $\begin{array}{c}\text { The amount of heat } \\
\text { removed from the synthesis } \\
\text { gas, } \mathbf{k W}\end{array}$ & $\begin{array}{c}\text { Heat which can be } \\
\text { utilized usefully, } \\
\mathbf{k W}\end{array}$ & $\begin{array}{c}\text { Power } \\
\text { consumption, } \mathbf{k W}\end{array}$ \\
\hline 0.1 & 51.91 & 50.63 & 26.6 \\
\hline 2 & 29.79 & 48.7 & 18.9 \\
\hline 3 & 25.34 & 35.3 & 9.94 \\
\hline
\end{tabular}

\section{Conclusion}

Analysis of the calculations shows that the increase in the process pressure and temperature results in decrease in the necessary energy costs for purifying the synthesis gas. The refrigerating coefficient at the pressure of synthesis gas of $2 \mathrm{MPa}$ is 1.58 , while it is 2.55 at a pressure of $3 \mathrm{MPa}$.

\section{References}

1. A.R. Bogomolov, S.A. Shevyrev, M.V. Alekseev, Thermal Power Eng. 2, 76 (2013)

2. G. Storch, Synthesis of hydrocarbons from carbon monoxide and hydrogen, 257 (1954)

3. A.V. Korobeinikov, Materials of the II All-Russian Youth Scientific and Practical Conference "Introduction to Energy", 23-25 November, Kemerovo (2016)

4. D. Leung, Renewable and Sustainable Energy Rev. 39, 426 (2014) 